\title{
AKTIVITAS FISIK DENGAN KUALITAS TIDUR LANSIA DI POSYANDU LANSIA WULAN ERMA MENANGGAL SURABAYA
}

\author{
Physical Activity With Sleep Quality In Elderly Posyandu Wulan Erma Menanggal \\ Surabaya
}

\author{
Fitri Nur Laili ${ }^{1}$, Nety Mawarda Hatmanti ${ }^{2}$ \\ ${ }^{1}$ Fakultas Keperawatan Dan Kebidanan \\ ${ }^{2}$ Program Studi S1 Keperawatan \\ Universitas Nahdlatul Ulama Surabaya \\ nety.mawarda@unusa.ac.id
}

\begin{abstract}
ABSTRAK
Aktifitas fisik merupakan gerakan tubuh dimana untuk melakukan sebuah gerakan itu, tubuh memerlukan tenaga yang cukup. Aktifitas fisik yang di lakukan dengan berlebihan akan mengakibatkan seseorang akan mudah mengalami kelelahan sehingga akan berdampak pada kualitas tidur lansia. Tujuan penelitian ini untuk mengetahui ada hubungan aktivitas fisik dengan kualitas tidur pada lansia di Posyandu Lansia Wulan Erma Kelurahan Menanggal Surabaya.

Desain penelitian ini menggunakan analitik dengan pendekatan cross sectional, Populasi 63 lansia di Posyandu Lansia Wulan Erma Kelurahan Menanggal Surabaya, sampel sebanyak 54 lansia di ambil dengan tekhnik probability sampling. Instrumen penelitian lembar kuesionar. Data dianalisis dengan uji ChiSquare dengan kemaknaan $\alpha=0,05$.

Penelitian ini menunjukkan bahwa dari 54 responden hampir setengahnya 23 responden $(42,6 \%)$ mempunyai aktifitas fisik yang baik dan sebagian besar 31 responden $(57,4 \%)$ mengalami aktivitas fisik yang kurang baik sedangkan hampir setengahnya 15 respoden $(27,7 \%)$ memiliki kualitas tidur yang baik dan sebagian besar 39 responden $(72,2 \%)$ mengalami kualitas tidur yang buruk. Terdapat hubungan antara aktivitas fisik dengan kualitas tidur pada lansia $(\rho=0,04)$

Aktivitas fisik yang baik dan teratur seperti senam lansia, jalan di pagi hari, lari cepat,mengangkat belanjaan, dan melakukan aktivitas rumah tangga. Aktivitas tersebut dapat membantu meningkatkan pola hidup yang sehat dan menjadikan kualitas tidur yang baik dan nyaman pada lansia.
\end{abstract}

Kata kunci: Aktivitas Fisik, Kualitas tidur, Lansia

\begin{abstract}
Physical activity is a movement in which the body to perform a movement, the body needs enough energy. Physical activity is done with excess will result in a person will be susceptible to fatigue so it will have an impact on the sleep quality of the elderly. The purpose of this study to determine the relationship of physical activity with the sleep quality in elderly Posyandu Elderly Wulan Erma Kelurahan Menanggal Surabaya.

Design of this study usinganalytic cross sectionalapproach,population of 63 elderly people at IHC Elderly Menanggal Surabaya Wulan Erma Kelurahan, a sample of 54 elderly shot with atechnique. probability samplingThe research instrument kuesionar sheet. Data were analyzed usingtest Chi-square with significance $\alpha=0.05$.

This study shows that nearly half of the 54 respondents 23 respondents (42.6\%) had good physical activity and the majority of the 31 respondents (57.4\%) experienced adverse physical activity, while almost half of 15 respondents (27.7\%) have a good sleep quality, and most of the 39 respondents (72.2\%) had poor sleep quality. There is a relationship between physical activity with the sleep quality in the elderly $(\rho=0.04)$

Physical activity is good and organized as gymnastics elderly, the road in the morning, sprinting, lifting groceries, and doing household activities. Such activity can help improve a healthy lifestyle and make good quality and comfortable sleep in the elderly.
\end{abstract}

Keywords: Physical activity, Sleep Quality, Elderly 


\section{PENDAHULUAN}

Lansia merupakan suatu proses penuaan yang terjadi pada setiap individu atau manusia dimulai sejak usia 65 tahun keatas yang ditandai dengan perubahan fisiologis, fisik, psikososial dan penurunan daya ingat (Maryam R.Siti, Mia Fatma Ekasari dkk, 2008). Aktivitas fisik yang terstruktur, terencana dan dapat dilakukan berulang disebut olahraga, namun aktivitas fisik yang kurang baik dapat mempengaruhi kesehatan tubuh dan fungsi organ yang lain. Sejalan dengan proses penuaan banyak perubahan yang dialami oleh lansia mulai perubahan fisik, psikologis, sosial, spiritual dan daya ingat.

Pada zaman sekarang ini banyak lansia yang kurang mengetahui tentang pentingnya aktivitas fisik apa saja yang baik dilakukan seperti senam lansia, memasak, menyapu dengan waktu yang sesuai. Tetapi banyak lansia yang masih kurang melakukan aktifitas seperti itu, akan tetapi lansia sering melakukan aktifitas fisik yang kurang baik bagi kesehatannya seperti mengepel lantai rumah, membersihkan debu pada jendela, mengasuh cucunya. aktifitas tersebut bisa mengakibatkan seorang lansia merasa ketidaknyamanan pada saat istirahat dan tidur. Kejadian seperti itu dapat mengakibatkan seorang lansia mengalami masalah seperti mudah capek, merasa lelah, letih, dan tidur kurang nyaman sehingga lansia juga mengalami gangguan tidur dan kualitas tidurnya.

Pada penelitian terdahulu yang dilakukan oleh Devi Oktaviana Habsari, heru sebektu, sri mulyani pada tahun 2014 dengan judul " Hubungan Aktivitas fisik dengan kualitas hidup pada lansia di desa margoagung kecamatan seyegen sleman Yogyakarta", dengan responden penelitian berjumlah 76 sampel didapatkan hasil bahwa ada hubungan yang signifikasn antara aktivitas fisik dan kualitas hidup serta terdapat perbedaan yang bermakna ditinjau dari domain Role Limitation due to physical health problems $(\mathrm{p}=0,001 ; \mathrm{p}+0,001)$, role limitation bodily pain $(\mathrm{p}=0,017 ; \mathrm{p}=0,019)$, vitality $(\mathrm{p}=0,001 ; \mathrm{p}=0,0001)$. Role limitation due to emotional problems $(\mathrm{p}=0,021 ; \mathrm{p}-$ $0,023)$.

Data Biro Sensus Amerika Serikat memperkirakan Indonesia akan mengalami peningkatan warga lansia terbesar di seluruh dunia pada tahun 1990-2025, yaitu sebesar $41,4 \%$. Penduduk usia lanjut di Indonesia pada tahun 2009 dapat mencapai 20,55 juta jiwa (Maryam R.Siti, Mia Fatma Ekasari,dkk, 2008). Menurut Badan Pusat Statistik (BPS) 2015 bahwa jumlah lansia di provinsi Jawa Timur sebesar 1.256.104 jiwa dengan kategori laki-laki berjumlah 744.038 jiwa dan perempuan berjumlah 512.066 jiwa. Sedangkan menurut BKKBN (2012) disebutkan bahwa penduduk Indonesia yang memasuki usia diatas 60 tahun sebesar 53.800 jiwa. Pada tahun 2020 diperkirakan akan mengalami kenaikan hingga 11,9\% dengan rata-rata usia harapan hidup sekitar 70 sampai 75 tahun. Berdasarkan hasil rekapan data pada tanggal 17 november 2016 diperoleh jumlah lansia di Posyandu Lansia Wulan Erma Kelurahan Menanggal Surabaya sebanyak 91 lansia dengan kategori usia pertengahan (middle age) yaitu usia 45 sampai 59 tahun sebanyak 15 lansia, usia lanjut (elderly) yaitu usia 60-74 tahun sebanyak 63 lansia dan usia tua (old) yaitu usia 75 sampai 87 tahun sebanyak 13 lansia.

Adapun faktor-faktor yang mempengaruhi kualitas tidur pada lansia adalah penyakit, lingkungan, latihan dan kelelahan, kecemasan, alkhohol, obat-obatan dan nutrisi. Latihan dan kelelahan dapat mempengaruhi kualitas dan kuantitas tidur karena keletihan akibat aktivitas yang tinggi seperti mengepel rumah, membersihkan debu di meja dan kursi, membersihkan halaman rumah.

Akibat aktivitas tersebut maka lansia akan memerlukan lebih banyak tidur untuk menjaga keseimbangan energi yang telah dikeluarkan. Hal tersebut dapat terlihat pada orang yang telah melakukan aktivitas dan mencapai kelelahan maka orang tersebut akan lebih cepat untuk dapat tidur karena tahap tidur gelombang lambatnya atau Non Rapid Eye Movement (NREM) diperpendek (Hidayat, 2008). Hal tersebut akan mengakibatkan ketidaknyamanan pada pola hidup lansia dan dapat menggangu kualitas tidur pada lansia karena lansia merasa pola tidurnya tidak maksimal. Pola hidup seperti itu sangat tidak bagus pada semua lansia yang melakukan aktivitas fisik secara berlebihan (Tamher S, 2009).

Berdasarkan uraian diatas upaya yang dapat dilakukan adalah menganjurkan dan mengatur waktu aktifitas fisik yang baik 
untuk dilakukan seorang lansia. Adapun aktifitas yang dapat dilakukan oleh seorang lansia seperti olahraga yang teratur,senam lansia, memasak, menyapu, dengan waktu yang sesuai. Dengan begitu lansia dapat melakukan aktivitas fisiknya secara teratur dan lansia dapat melakukan gerakan sesuai dengan kemampuannya sehingga kualitas tidurnya tetap terjaga.

\section{METODE PENELITIAN}

Jenis penelitian yang digunakan adalah metode cross sectional.

Populasi dalam penelitian ini adalah lansia dengan usia 60-74 tahun sebanyak 63 lansia yang ada di Posyandu Lansia Wulan Erma Kelurahan Menanggal Surabaya.

Cara pengambilan sampel dalam penelitian ini adalah menggunakan teknik probability sampling dengan tipe simple random sampling dengan besar sampel 54 responden. Variabel bebas dalam penelitian ini adalah aktivitas fisik. Variabel tergantung pada penelitian ini adalah kualitas tidur.

Instrumen dalam penelitian ini adalah menggunakan alat ukur lembar kuesioner, dimana kuesioner PASE (Physical Activity Scale Elderly) untuk mengetahui aktivitas fisik lansia (variabel independen) dan kuesioner PSQI (Pitsburgh Scale Quality Index) untuk mengetahui kualitas tidur lansia (variabel dependen). selanjutnya dianalisis dengan chi square.

\section{HASIL PENELITIAN}

1. Data Umum

a. Karakteristik responden berdasarkan usia Tabel 5.1 Distribusi frekuensi responden berdasarkan usia

\begin{tabular}{cccc}
\hline No. & $\begin{array}{c}\text { Usia } \\
(\text { tahun) }\end{array}$ & Frekuensi (n) & $\begin{array}{c}\text { Persentase } \\
(\%)\end{array}$ \\
\hline 1 & $45-59$ & 9 & 16,7 \\
2 & $60-74$ & 39 & 72,2 \\
3 & $75-90$ & 6 & 11,1 \\
\hline & Jumlah & 54 & 100,0 \\
\hline
\end{tabular}

Sumber : Data Primer 2017

Berdasarkan tabel 5.1 menunjukkan hampir seluruhnya responden $(72,2 \%)$ berusia 60-74 tahun (elderly) b. Karakteristik responden berdasarkan jenis kelamin

Tabel 5.2. Distribusi frekuensi responden berdasarkan jenis kelamin

\begin{tabular}{cccc}
\hline $\begin{array}{c}\mathrm{N} \\
\mathrm{o}\end{array}$ & $\begin{array}{c}\text { JenisKelami } \\
\mathrm{n}\end{array}$ & $\begin{array}{c}\text { Frekuensi } \\
(\mathrm{n})\end{array}$ & $\begin{array}{c}\text { Persenta } \\
\text { se }(\%)\end{array}$ \\
\hline 1. & Laki - laki & 17 & 31,5 \\
2. & Perempuan & 37 & 69,5 \\
\hline & Jumlah & 54 & 100,0
\end{tabular}

Sumber : Data Primer 2017

Berdasarkan tabel 5.2 menunjukkan sebagian besar responden $(69,5 \%)$ berjenis kelamin perempuan

c. Karakteristik responden berdasarkan Pekerjaan

Tabel 5.3 Distribusi frekuensi responden berdasarkan pekerjaan

\begin{tabular}{clcc}
\hline No. & $\begin{array}{c}\text { Pekerjaan } \\
\text { Lansia }\end{array}$ & $\begin{array}{c}\text { Frekuensi } \\
(\mathrm{n})\end{array}$ & $\begin{array}{c}\text { Persentase } \\
(\%)\end{array}$ \\
\hline 1 & Wiraswasta & 5 & 9,3 \\
2 & Ibu rumah & 29 & 53,7 \\
& tangga & & \\
3 & Pensiun & 15 & 27,8 \\
4 & Pegawai & 2 & 3,7 \\
& Negeri & 3 & 5,6 \\
5 & $\begin{array}{l}\text { Pegawai } \\
\text { Swasta }\end{array}$ & 34 & 100,0 \\
\hline & Jumlah & 54
\end{tabular}

Sumber : Data Primer 2017

Berdasarkan tabel 5.3 menunjukkan sebagian besar responden (53,7\%) pekerjaannya sebagai ibu rumah tangga.

d. Karakteristik responden berdasarkan obat yang di konsumsi

Tabel 5.4 Distribusi frekuensi responden berdasarkan obat yang sering di konsumsi

\begin{tabular}{clcc}
\hline No. & $\begin{array}{c}\text { Obat yang } \\
\text { sering di } \\
\text { konsumsi }\end{array}$ & $\begin{array}{c}\text { Frekuens } \\
\mathrm{i}(\mathrm{n})\end{array}$ & $\begin{array}{c}\text { Persentas } \\
\mathrm{e}(\%)\end{array}$ \\
\hline 1 & Obat & 12 & 22,2 \\
2 & hipertensi & 42 & 77,8 \\
& Tidak & & \\
& mengkonsum & & \\
& si obat & & 100,0 \\
\hline & Jumlah & 54 & \\
\hline
\end{tabular}

Sumber : Data Primer 2017

Berdasarkan tabel 5.4 menunjukkan hampir seluruhnya responden $(77,8 \%)$ tidak mengkonsumsi obat sebelum tidur 
e. Karakteristik responden berdasarkan pendidikan terakhir

Tabel 5.5 Distribusi frekuensi responden berdasarkan tingkat pendidikan

\begin{tabular}{|c|c|c|c|}
\hline No. & Pendidikan & $\begin{array}{l}\text { Frekuensi } \\
\text { (n) }\end{array}$ & $\begin{array}{c}\text { Persentase } \\
(\%)\end{array}$ \\
\hline 1 & $\begin{array}{l}\text { Dasar (SD- } \\
\text { SMP) } \\
\text { sederajat } \\
\text { Tinggi }\end{array}$ & 16 & 29,7 \\
\hline 2 & $\begin{array}{l}\text { Menengah } \\
\text { (SMA) } \\
\text { Sederajat }\end{array}$ & 30 & 55,6 \\
\hline 3 & $\begin{array}{l}\text { Perguruan } \\
\text { Tinggi }\end{array}$ & 8 & 14,8 \\
\hline & Jumlah & 54 & 100,0 \\
\hline
\end{tabular}

Sumber : Data Primer 2017

Berdasarkan tabel 5.5 menunjukkan sebagian besar responden $(55,6 \%)$ pendidikan terakhirnya adalah Menengah (SMA) sederajat

f. Karakteristik responden berdasarkan penyakit yang di derita responden

Tabel 5.6 Distribusi frekuensi responden berdasarkan penyakit yang di derita

\begin{tabular}{clcc}
\hline No. & $\begin{array}{c}\text { Penyakit } \\
\text { yang di } \\
\text { derita }\end{array}$ & $\begin{array}{c}\text { Frekuensi } \\
(\mathrm{n})\end{array}$ & $\begin{array}{c}\text { Persentase } \\
(\%)\end{array}$ \\
\hline 1 & Hipertensi & 30 & 55,6 \\
2 & Asam & 11 & 20,4 \\
& Urat & & 7,4 \\
3 & Kolesterol & 4 & 16,7 \\
4 & Sehat & 9 & 100,0 \\
\hline
\end{tabular}

Sumber : Data Primer 2017

Berdasarkan tabel 5.6 menunjukkan sebagian besar responden $(55,6 \%)$ mengalami hipertensi.

\section{g. Data Khusus}

Tabel 5.7. Distribusi frekuensi berdasarkan aktivitas fisik lansia

\begin{tabular}{llcc}
\hline No. & $\begin{array}{l}\text { Aktivitas } \\
\text { lansia }\end{array}$ & $\begin{array}{c}\text { Frekuensi } \\
(\mathrm{n})\end{array}$ & $\begin{array}{c}\text { Persentase } \\
(\%)\end{array}$ \\
\hline 1 & Baik & 23 & 42,6 \\
2 & Kurang & 31 & 57,4 \\
& Baik & & \\
\hline & Jumlah & 54 & 100,0 \\
\hline
\end{tabular}

Sumber : Data Primer 2017

Berdasarkan tabel 5.7 menunjukkan

sebagian besar responden $(57,4 \%)$ mengalami aktivitas fisik yang kurang baik. a. Karakteristik responden berdasarkan Kualitas Tidur
Tabel 5.8
Distribusi frekuensi berdasarkan Kualitas Tidur

\begin{tabular}{cccc}
\hline No. & $\begin{array}{c}\text { Kualitas } \\
\text { Tidur }\end{array}$ & $\begin{array}{c}\text { Frekuensi } \\
(\mathrm{n})\end{array}$ & $\begin{array}{c}\text { Persentase } \\
(\%)\end{array}$ \\
\hline 1 & Baik & 15 & 27,7 \\
2 & Buruk & 39 & 72,2 \\
\hline & Jumlah & 54 & 100,0
\end{tabular}

Sumber : Data Primer 2017

Berdasarkan tabel 5.8 menunjukkan

sebagian besar responden (72,2\%) mengalami kualitas tidur yang buruk.

b. Hubungan Aktivitas Fisik dengan Kualitas Tidur pada Lansia di Posyandu Lansia Wulan Erma Kelurahan Menanggal Surabaya.

Tabel 5.9. Tabulasi silang Aktivitas Fisik dengan Kualitas Tidur

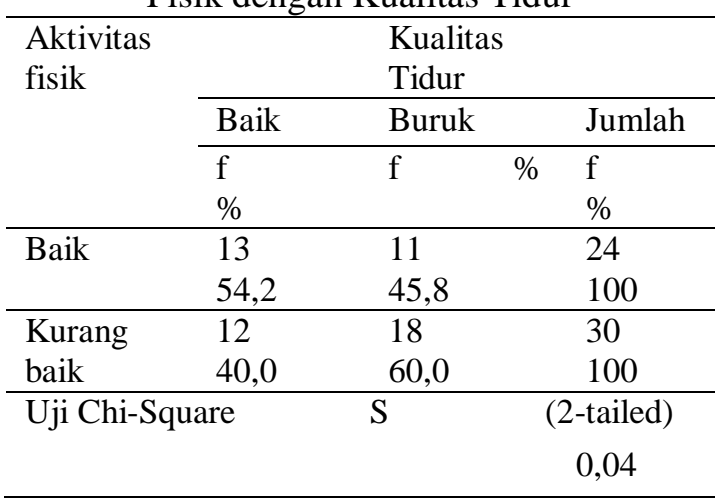

Tabel 5.9 menunjukkan bahwa dari 24 responden sebesar 13 responden yang memiliki aktivitas fisik baik, sebagian besar $(54,2 \%)$ responden memiliki kualitas tidur yang baik sedangkan 30 responden yang memiliki aktivitas fisik kurang baik, hamper seluruhnya $(60,0 \%)$ responden memiliki kualitas tidur buruk.

Setelah dilakukan uji Chi-Square dengan tingkat kemaknaan $\alpha=0,05$ dengan bantuan SPSS for windows 23. Didapatkan $\rho$ $=0,04<\alpha=0,05$ yang menunjukkan bahwa H0 ditolak bila $\rho<\alpha$ yang artinya ada hubungan aktivitas fisik dengan kualitas tidur pada lansia di Posyandu Lansia Wulan Erma Kelurahan Menanggal Surabaya.

\section{PEMBAHASAN}

\section{A. Aktivitas Fisik Lansia}

Hasil penelitian yang dilakukan peneliti menunjukkan bahwa sebagian besar 31 $(57,4 \%)$ responden memiliki aktivitas fisik yang buruk. Hasil ini menunjukkan bahwa 
sebagian besar responden mempunyai aktivitas fisik yang tergolong kurang baik dalam kehidupan sehari-harinya. Aktivitas fisik kurang yaitu aktivitas fisik yang dilakukan hanya memerlukan sedikit tenaga dan biasanya tidak menyebabkan perubahan dalam pernapasan atau ketahanan (endurance). Berdasarkan hasil pembagian kuesioner PASE didapatkan bahwa banyak lansia yang melakukan aktifitas yang kurang baik di pernyataan pertama bahwa $55,6 \%$ lansia melakukan aktivitas fisik dengan durasi waktu yang lama yaitu 1-10 jam dalam satu minggu dan ke delapan, ini dibuktikan dengan banyaknya lansia yang melakukan aktifitas yang berat yaitu merawat cucunya setiaap hari selama 4-6 jam dalam sehari dan aktifitas ini dilakukan setiap hari oleh lansia. Berdasarkan hasil penelitian hampir seluruh lansia yang berada di Posyandu Lansia memiliki aktivitas fisik yang kurang disebabkan karena adanya keterbatasan lansia dalam melakukan aktivitas seharihari.Faktor-faktor yang mempengaruhi aktivitas fisik yaitu usia, kesehatan fisiologis, fungsi kognitif, fungsi psikologis, dan aktivitas.

Berdasarkan tabel 5.1 menunjukkan bahwa dari 54 responden hampir seluruhnya $39(72,2 \%)$ responden berusia 60-74 tahun (elderly). Hal ini dapat disebabkan karena usia di atas 50 tahun memiliki risiko lebih tinggi menderita penyakit, karena terdapat perubahan fisiologi penuaan yang berpengaruh pada organ-organ tubuh termasuk sistem muskuloskeletal dimana pada lansia tulang akan kehilangan kepadatan dan makin rapuh, pergerakan pinggang, lutut dan jari-jari pergelangan terbatas, persendian membesar dan menjadi kaku, tendon mengerut dan mengalami skelerosis. Terjadi atropi serabut otot (otot-otot serabut mengecil) sehingga pergerakan menjadi lamban, otot-otot menjadi kram dan tremor. Oleh karena itu usia adalah salah satu faktor yang dapat mempengaruhi aktivitas fisik. Berdasarkan hasil pembagian kuesioner PASE bahwa sebagian besar lansia di Posyandu Lansia Wulan Erma Kelurahan Menangggal Surabaya tidak pernah melakukan aktifitas fisik yang berat untuk meningkatkan kekuatan ototnya seperti mengangkat beban atau push up. Lansia terbukti tidak melakukan aktifitas fisik ini di karenakan oleh beberapa faktor seperti usia dan penyakit yang sedang di alaminya seperti hipertensi, asam urat dan kolestrol

\section{B. Kualitas Tidur Lansia}

Hasil penelitian pada tabel 5.8 menunjukkan bahwa dari 54 respondenhampir setengahnya $15(27,7 \%)$ mempunyai kualitas tidur yang baik. Sedangkan hampir seluruhnya $(72,2 \%)$ responden mempunyai kualitas tidur yang buruk. Dapat disimpulkan bahwa hampir seluruhnya responden mempunyai kualitas tidur yang buruk. Pada lansia biasanya membutuhkan waktu 30-60 menit untuk memulai tidur dan biasanya terbangun terlalu pagi. Bedasarkan hasil pembagian kuesioner PSQI didapatkan bahwa banyak lansia yang memiliki efisiensi tidur yang buruk di komponen pertama, ini dibuktikan dengan banyaknya lansia yang terbangun terlalu pagi. Berkurangnya durasi waktu tidur mempengaruhi efisiensi tidur. Komponen dua tentang latensi tidur juga lemah karena banyak lansia yang kesulitan untuk memulai tidur, lansia membutuhkan waktu lebih dari 30 menit untuk bisa tidur. Komponen 3 yaitu lansia banyak mengalami gangguan tidur pada malam hari, lansia biasanya terbangun untuk kekamar mandi, merasa kepanasan atau kedinginan, batuk dan terasa nyeri yang dirasakan di daerah tubuhnya. Hal ini menunjukkan bahwa dengan kualitas tidur yang tidak adekuat dapat mengurangi oksigen yang akan masuk ke dalam darah. Pada saat tidur tubuh akan mendapatkan oksigen yang optimal sehingga darah akan kaya dengan oksigen dapat mengalir ke selebral di hipocampus pada otak dimana tempat penyimpanan memori jangka pendek akan maksimal, dengan mengurangi kualitas tidur maka oksigen yang masuk menjadi kurang optimal. Menjaga kualitas tidur yang adekuat juga mempengaruhi kejadian anemia. Menurut Potter \& Perry (2006) lansia yang mempunyai kadar $\mathrm{Hb}$ di dalam darah lebih rendah dari nilai normal dapat menyebabkan menurunnya daya ingat ataupun berkurangnya kemampuan untuk berkonsentrasi. Untuk dapat mempertahankan daya ingat dan kemampuan untuk berkonsentrasi diperlukan energi yang tersedia dalam tubuh yaitu dengan memperhatikan kualitas tidur yang adekuat.

Hasil penelitian pada tabel 5.1 menunjukkan bahwa dari 54 repsonden usia 60-74 tahun hampir seluruhnya $(72,2 \%)$ 
mempunyai kualitas tidur yang buruk. Menurunnya kualitas tidur pada lansia juga dipengaruhi oleh bertambahnya usia karena menurut Stanley (2006) menurunnya kualitas tidur pada lansia juga berhubungan erat dengan proses degeneratif yang dialami seperti penurunan jumlah dan ukuran neuron pada sistem saraf pada lansia, menyebabkan tidak optimalnya fungsi neurontransmiter yang berhubungan dengan penghantar signal ke otak di kelenjar pienal. Penurunan melatonin yang berpengaruh terhadap perubahan irama sirkadian yang menyebabkan penurunan kualitas tidur lansia. Faktor yang dapat berhubungan dengan kualitas tiduryang burukt pada lansia diantaranya faktor penyakit, lingkungan, kelelahan, gaya hidup dan stres emosional. Menurut peneliti dari hasil penelitian menunjukkan bahwa lansia yang mempunyai kualitas tidur yang buruk berada pada usia 60-74, menunjukkan bahwa pada usia tersebut lansia mempunyai faktor lain seperti kelelahan akibat pekerjaan, gaya hidup yang membuat waktu tidur lansia berkurang dan stress emosional akibatnya membuat lansia memiliki kualitas tidur yang tidak adekuat.

Hasil penelitian pada tabel 5.6 menunjukkan bahwa sebagian besar responden $(55,6 \%)$ mengalami sakit hipertensi, sebagian kecil responden $(20,4 \%)$ menderita sakit asam urat, sebagian kecil responden $(7,4 \%)$ menderita sakit kolestrol dan sebagian kecil responden $(16,7 \%)$ dalam keadaan sehat. berdasarkan hasil penelitian tersebut maka dapat disimpulkan bahwa lansia yang ada di Posyandu Lansia Wulan Erma Kelurahan Menanggal Surabaya dalam keadaan sehat.kualitas tidur seorang lansia dapat di pengaruhi oleh penyakit yang di alaminya seperti halnya lansia sering terbangun di malam hari untuk ke kamar mandi dan terkadang lansia mengeluh kesemutan di bagian lutut dan jari-jari tangannya atau kakinya. Opini ini juga dapat dikuatkan dengan teori menurut Asmita (2015) mengatakann bahwadurasi tidur yang pendek selain dapat meningkatkan rata-rata tekanan darah dan denyut jantung juga meningkatkan aktivitas sistem syaraf simpatik dan merangsang stres fisik dan psikososial, pada akhirnya bisa mengakibatkan hipertensi berkelanjutan. Selain itu, gangguan pada ritme sikardian dan keseimbangan otonom akibat sering tidur dengan durasi yang pendek juga merupakan salah satu faktor potensial dalam mekanisme ini. Durasi tidur yang pendek juga terkait dengan perubahan emosi seperti mudah marah, pesimis, tidak sabar, lelah dan stres, yang akan membuat seseorang lebih sulit mempertahankan gaya hidup sehat sehingga meningkatkan risiko hipertensi.

\section{SIMPULAN}

1. Lansia yang ada di Posyandu Lansia Wulan Erma Kelurahan Menanggal Surabaya sebagian besar mengalami aktivitas fisik yang kurang baik dan sebagian besar lansia juga mengalami kualitas tidur yang buruk

2. Lansia yang ada di Posyandu Lansia Wulan Erma Kelurahan Menanggal Surabaya sebagian besar lansia mengalami kualitas tidur yang buruk

3. Terdapat hubungan antara aktivitas fisik dengan kualitas tidur pada lansia di Posyandu Lansia Wulan Erma Kelurahan Menanggal Surabaya

\section{SARAN}

1. Kepada kepala Posyandu lansia Wulan Erma Kelurahan Menanggal Surabaya Diharapkan aktivitas fisik yang baik dapat diterapkan kembali pada lansia di posyandu lansia tersebut. Kegiatan rutin senam lansia juga sebaiknya dipertahankan demi menjaga kesehatan dan daya tubuh lansia agar tetap sehat dan bugar.

2. Kepada institusi

Dapat digunakan sebagai masukan tentang hubungan aktivitas fisik dengan kualitas tidur pada lansia.

3. Kepada Peneliti selanjutnya

Dapat digunakan sebagai bahan referensi dalam penelitian selanjutnya.

\section{DAFTAR PUSTAKA}

Arbiadiani.(2016). Kuesioner PASE. http://documentslide.com/documents /bab-ii-56c10d1dc02d3.html\# diakses pada tanggal 15 februari 2016

Arikunto, S. (2008). Prosedur penelitian suatu pendekatan praktik. Rineka Cipta, Jakarta

Asmadi. (2008). Konsep dan Kesehatan Dasar Klien. Jakarta. Rineka Cipta 
Asmita,(2015) Hubungan Kualitas Tidur dengan Teakanan Darah pada Usia lanjut di Posyandu Lansia Dusun Jelapan Sindumartani Ngemplak Sleman Yogyakarta

Asmarita, Intan. Hubungan Antara Kualitas Tidur Dengan Tekanan Darah Pada Pasien Hipertensi Di Rumah Sakit Umum Daerah Karanganyar. Diss.Universitas Muhammadiyah Surakarta, 2014.

Azizah, Lilik Ma'rifatul.(2011). Keperawatan Lanjut Usia. Edisi Pertama. Yogyakarta : Graha Ilmu

Aspiani, Reny Yuli. (2014). Buku Ajar Asuhan Keperawatan Gerontik Aplikasi Nanda, NIC dan NOC. Jakarta : Trans Info Media

Badan Pusat Statistik. (2015). Statistik Penduduk Lanjut Usia. Jakarta : BPS

BKKBN. (2012). Skala Data Lansia Di Indonesia. Jakarta : BKKBN

Diakses

https://www.google.co.id/webhp?ie $=$ utf. Pada tanggal 16 November 2012

Dewi, Sosia Rhosma.(2014).Buku Ajar Keperawatan Gerontik. Edisi 1, Cetakan Pertama :Yogyakarta

Fatmah. (2010). Gizi usia lanjut. Jakarta : PT.Penerbit Erlangga

Hesti Widuri, Sujono Riyadi. (2010). Kebutuhan dasar manusia (aspek mobilitas dan istirahat tidur). Yogyakarta: Gosyen Publishing

Hidayat,A.Aziz Alimul.(2012). Pengantar kebutuhan manusia aplikasi konsep dan proses keperawatan. Jakarta :Salemba Medika

Hidayat, Aziz Alimul. (2016). Buku Ajar Ilmu Keperawatan Dasar. Jakarta: Salemba Medika

Ismayanti, S. N. (2013). Hubungan Antara Pola Konsumsi dan Aktivitas Fisik dengan Status Gizi Pada Lansia di Panti Sosial Tresna Werdha

$\begin{array}{crr}\text { Maryam R.Siti, } & \text { Mia } & \text { Fatma } \\ \text { Ekasari,dkk.(2008).Mengenal } & \text { Usia }\end{array}$

Lanjut dan perawatannya. Jakarta:Salemba Medika

McIntyre, Patrick.(2010). Methods of physical activity assessment for older adults. M.S. Thesis, Iowa State University: USA. Di akses pada bulan Juli 2012 di http://lib.dr.iastate.edu/cgi/viewconte nt.cgi $?$ article $=3816 \&$ context $=$ etd

Mubarak,et al.(2011). Ilmu Keperawatan Komunitas Konsepdan Aplikasi. Jakarta: Salemba Medika

Nafida, Nur.(2014). Hubungan antara aktivitas fisik dengan Tingkat kognitif lanjut usia di panti social Tresna werdha budi mulia 4 margaguna Jakarta Selatan. Program studi ilmu keperawatan fakultas kedokteran dan ilmu kesehatan universitas islam negeri syarif hidayatullah.

Nugroho, Wahyudi. (2009). Komunikasi dalam keperawatan Gerontik. Jakarta: EGC

Nursalam. (2013). Metodologi Penelitian Ilmu Keperawatan: Pendekatan Praktis Edisi 3. Jekarta; Salemba Medika

Oktavianus. (2014). Asuhan Keperawatan Pada Sistem Neurobehavior. Yogyakarta: Graha Ilmu

Potter \& Perry.(2005).Buku Ajar Fundamental Keperawatan : Konsep, Proses dan Praktik. Jakarta :EGC

Potter \& Perry. (2009). Fundamental of Nursing Fundamental Keperawatan Buku 1 Edisi 7. Jakarta : Salemba Medika

Pranama, Vendrik Fhajar.(2012). Hubungan Aktivitas Fisik Dengan Tekanan Darah Pada Lansia Hipertensi Di Desa Pomahan Kecamatan Pulung Kabupaten Ponorogo. Universitas Muhammadiyah Ponorogo

Sari, Mega Nurul Laili Purwita. (2014). Hubungan Aktivitas Fisik dan Aktivitas Kognitif Terhadap Kejadian Demensia Pada Lansia Kecamatan Boja. 
Setiati, S., Harimurti, K., dan Roosheroe, A.G.(2009).Proses Menua dan Implikasi Kliniknya.Dalam: Sudoyo, A.W., Setiyohadi, B., Alwi, I., Simadibrata, M., dan Setiati, S., ed. IV Buku Ajar Ilmu Penyakit Dalam. Jakarta: Pusat Penerbitan Ilmu Penyakit Dalam Fakultas Kedokteran Universitas Indonesia, 1335-1340.

Tamher, S. (2009). Kesehatan Usia Lanjut dengan Pendekatan Asuhan Keperawatan. Jakarta; Salemba Medika

Tarwoto, Wartonah. (2015). Kebutuhan dasar manusia dan proses keperawatan. Jakarta : Salemba Medika

Washburn RA, Montoye H.( 1986) The assessment of physical activity by questionnaire. Am J Epidemiol. Di akses http://www.physiopedia.com/Physical_Activity_Scale_ for_the_Elderly_(PASE)

Widiastuti, Yuli.(2015). Hubungan antara kualitas tidur lansia dengan tingkat kekambuhan pada pasien hipertensi di klinik dhanang husada sukoharjo. Dikutip oleh Diss. Stikes Kusuma Bangsa. 2016. diakses di http://journal.uny.ac.id/index.php/me difora/article/viewFile/2816/2342 